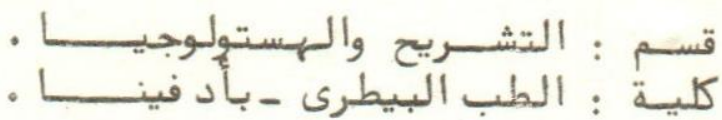

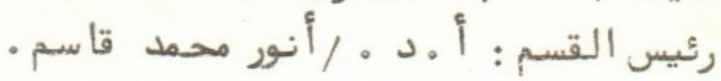

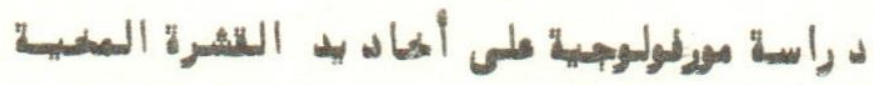

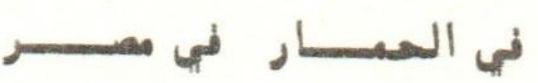

عبد الله حفنسي ، عبد السلام حموده ه ، على د غباج

في هـذه الد راسة تم تشريح المخ في عشرة حمير بالغـة لد راسة عـــد د

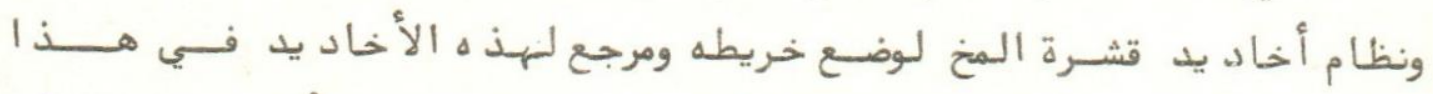

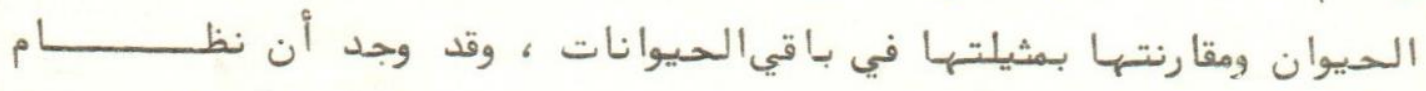

?

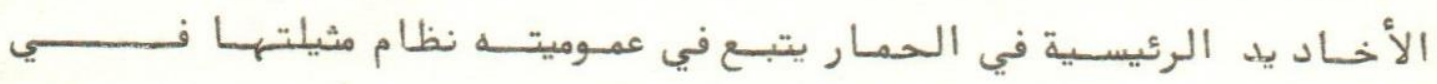

الحصسان ، غير أن بعسض الاختـلافات يمكن ملاحظتهـا في التفاصيل .

3 
Dept. of Anatomy and Histology,

Fac. of Vet. Med., Assiut University,

Head of Dept. Prof. Dr. H.N. Badawi.

\title{
MORPHOLOGICAL STUDY ON THE SULCI OF THE NEOPALLUM OF THE DONKEY IN EGYPT.
}

(With 3 Figures)

\author{
By \\ A. HIFNY, A.K. HEMMODA* and A. DOUGBAGE* \\ (Received at 20/6/1984)
}

\begin{abstract}
SUMMARY
The cerebral sulci were studied on ten adult donkeys in order to establish an index reference for the pattern of these sulci. The present study shows that the prinicipal cerebral sulci of the donkeys are generally similar to those of the horse, however variations in some details be observed.
\end{abstract}

\section{INTRODUCTION}

Concerning the neopallium of the equine, many authors dealed with that of the horse (BRADLEY/GRAHAME, 1947; SISSON/GROSSMAN, 1969, as well as DELLMANN/McCLURE, 1975) but nothing about the neopallium of the donkey. So the present study as descriptive work tries to conduct the progress in establish the structural characteristics of the brain of the donkeys which may help in futher studies in veterinary fields and its comparison with brains of the other animals particularly with the horse.

\section{MATERIAL and METHODS}

Ten brains from adult donkeys of different age and sex, were used. The brains were taken from embalmed carcasses and injected with 10\% formalin. The dura mater was removed by careful dissection and the sulci were described. The nomenclature employed in this work based on the Nomina Anatomica Veterinaria (1973).

\section{RESULTS}

The neopallium was thrown into gyri separated by a series of sulci which are more regular on the medial surface than the dorsolateral one and they were not usually of bilateral symmetry. The neoplaiium is separated from the rhinencephalon by the suclcus rhinalis lateralis and medialis, the first one is subdivided by the cerebral fossa into rostral and caudal parts. The rostral part (1/14) runs rostrally between the rhinencephalon ventrally and the insular gyri dorsally to terminate in the concavity of the prorean gyrus. The caudal part of the lateral rhinal sulcus $(1 / 15)$ runs between the rhinencephalon and the neopallium to terminate at the tentorial surface of the cerbral hemisphere ventrolaterally or may be extended to reach the occipital gyrus. The medial rhinal sulcus $(3 / 13)$ is in continuation with the lateral rhinal sulcus at the concavity of the prorean gyrus and passes caudoventrally between the rhinencepalon ventrally and the medial limb of the prorean gyrus dorsally to terminate at the subcallosal gyrus.

* : Dept. of Anatomy, Histology and Embryology,

Fac. of Vet. Med., Edfina-Rashid line-Alex.

Head of Dept. Prof. Dr. A.M. Kassem.

Assiut Vet. Med. J. Vol. 14, No. 28, 1985. 


\section{A. HirNY, et alo}

The medial surface of the neopallium is -separated from the corpus callosum by sulcus corporis callosi $(3 / 7)$ which begins at the ventral end of the sulcus genualis and curves around the genu of the corpus callosum and runs caudally along its body to gain the splenium where it curves rostroventrally to terminate beneath the splenium. In six cases the sulcus corporis callosi is located directly above to the corpus callosum but in four cases it was found between the cingular gyrus and the suprocallosal gyrus. In two cases the sulcus corporis collosi was in continuation with the endogenual sulcus at the rostral end of the genu corpus callosi.

The principal sulci which are described from formalized hemispheres are as follows:

Fissura sylvia $(1 / 1)$ is considered as direct continuation of the vallecula lateralis cerebri, and is occupied by the insular gyrus. The sylvian fissure gives dorsally 3 branches, the rostral one $(1 / 2)$ is the longest and is directed rostrodorsally, the middle $(1 / 3)$ is the shortest and vertical, while the caudal $(1 / 3)$ one is directed caudodorsally.

The sulcus ectosylvius can be divided into three parts, rostral middle and caudal ectosylvian sulci. The rostral and middle ectosylvian sulci $(1 / 7$ \& 8$)$ form a continuous sulcus which runs between the rostral two thirds of the ectosylvian and sylvian gyri, these rostral and middle sulci are separated by narrow depressed gyrus connecting the two gyri. However the caudal ectosylvian sulcus $(1 / 9)$ lies between the caudal part of the mentioned gyri and is separated from the middle one by the oblique sulcus $(1 / 10)$.

The sulcus presylvius $(1 / 5)$ extends from the sylvian fissure and runs rostrally and medially paralled to the prorean sulcus to gain the lateral aspect of the postcruciate gyrus where it continues with the suprsylvian sulcus.

Sulcus proreus $(1 / 6)$ begins at the rostral aspect of the insular gyri and runs rostrodorsally along the caudal aspect of the prorean gyrus to terminate at the rostral aspect of the precruciate gyrus. In two cases the prorean sulcus was interrupted by a narrow gyrus connecting between the prorean gyrus and the insular gyri.

The sulcus suprasylvius $(1 / 11,12,13)$ is the longest and deepest sulcus of the convex surface. It begins at the caudal pole of the cerebral hemisphere dorsal to the tectum and runs caudodorsald to gain the convex surface where it runs in an undulating manner in rostral direction to join the ansate sulcus medially and the presylvian sulcus rostrally. In seven cases the suprasylvian sulcus is separated from the presylvian sulcus by a narrow gyrus at the junction of the rostral two thirds of the cerebral hemisphere. From the topographical point of view the continuous suprasylvian sulcus can be divided into rostral, middle and caudal suprasylvian sulci.

Sulcus obliquus $(1 / 10)$ begins at the junction of the caudal two thirds of the suprasylvian suicus and runs ventrally between the rostral and caudal oblique gyri to gain the caudal part of the lateral rhenal sulcus or the caudal branch of the sylvian fissure. In one case the oblique sulcus was interrupted by two narrow gyri, connecting between the restral and caudal oblique gyri at their middle.

Sulcus marginalis $(2 / 1)$ is situated on the caudal half of the $d$-sal border parallel to the longitudinal cerebral fissure. At the caudal pole it runs somewhat caudolaterally and ventrally. it is limited rostrally by the gyrus communicating between the marginal and the ectomarginal gyri, and terminates caudally by a very short, transverse part rostral to the occipital gyrus. 


\section{THE SULCI OF THE NEOPALLUM OF THE DONKEY IN EGYPT}

Sulcus ectomarginalis is a sagittal sulcus $(1 / 16, " / 3)$ which is separated from the marginal sulcus by the wide medial part of the ectomarginal gyrus, and terminates caudally at the occipital gyrus. It is limited rostrally and caudally by the communicating gyrus between the medial and lateral parts of the ectomarginal gyrus.

Sulcus endomarginalis $(2 / 2)$ is a sagittal sulcus at the caudal thirds of the cerebral hemisphere and is limited by the medial and lateral parts of the marginal rostroventrally to terminate at the transverse cerebral fissure above the tectum. In two cases the endomarginal sulcus was separated from the transverse fissure by a narrow gyrus.

Sulcus ansatus $(2 / 4,3 / 1)$ begins from the splenial sulcus at the junction of the caudal two thirds of the medial surface of the cerebral hemisphere. It runs rostrodorsally and laterally to cross the dorsal border of the cerebral hemisphere rostral to the marginal gyrus to continue with the suprasylvian sulcus.

The sulcus cruciatus $(2 / 6,3 / 2)$ is a small transeverse sulcus which originates from the splenial sulcus, at the junction of the cranial two thirds of the cerebral hemisphere and crosses its dorsal border.

The sulcus genualis $(3 / 4)$ is situated caudodorsal to the rostral internal sulcus at the rostral pole of the hemisphere, it runs caudodorsally to continue with the splenial sulcus.

The sulcus splenialis $(3 / 5)$ is the caudal continuation of the genual sulcus and is separated from the sulcus corporis callosi by the cingular gyrus. It runs caudally parallel to the body of the corpus callosum and continues as the calcarinus sulcus.

The sulcus calcarinus $(3 / 6)$ curves around the caudal part of the cingular gyrus and runs caudoventrally then rostoventrally and laterally, where it joins the caudal end of the endomarginal sulcus. It is separated from the caudal part of the lateral rhinal sulcus by a narrow gyrus. In 6 cases the rostral and caudal parts of the cingular gyrus are divided into two parts by endosplenial and end genual sulci respectively, and in two of the 6 cases the endogenual and endosplenial sulci were in continuation.

The sulcus rostralis internus $(3 / 3)$ is the smallest sulcus on the medial surface of the cerebral hemisphere. It is situated on the ventrorostral part of this surface. It forms the caudal boundary of the medial limb of the prorean gyrus, and is separated from the beginning of the genual sulcus by very narrow gyrus.

\section{DISCUSSION}

The fissura sylvia in the brain of the donkey represents the direct continuation of the lateral cerebral fossa, which in agreement to that obtained by DELLMANN/McCLURE (1975) in horse, EL-KHLIGI (1977) and MANSOUR (1983) in camel, however in case of ox RAGHAVAN/KACHROO (1964) mentioned that the fissura sylvia begins, at the base of the brain, in the form of a transverse depression lateral to the anterior perforating substance. In Indian buffalo RAO/SHARMA (1974) stated that this Fissure arises above the vallecula lateralis cerebri. Regarding the division of the fissura sylvia into 3 branches, rostral, middle, and caudal, the present work is in agreements with DEL MANN/McCLURE (1975) in horse and large ruminants, KANAN (1973) in camel, RAGHAVAN/KACHROO (1964) in ox, as well as RAO/SHARMA (1974) in Indian buffalo who added that the anterior and posterior branches are not prominant.

The division of the ectosylvian sulcus into three parts which continue with each other are similar to that recorded in camel (El-KHALIGI, 1977) sheep (MAY, 1970) goat KAMIN,

Assiut Vet. Med. J. Vol. 14, No. 28, 1985. 
1984) and in the dog (MEYER, 1964). However in Indian buffalo (RAO/SHARMA, 1974), Egyptian buffalo (EL-NAHLA, 1982) as well as in the camel (MANSOUR, 1983) the ectosylvian sulcus is divided into rostral and caudal parts only. BRADLEY/GRAHAME (1947) recorded that in the brain of the horse the ectosylvian sulcus forms a bent around the middle branch of the sylvian Fissure. DELLMANN/MCCLURE (1975) added that the ectosylvian sulcus in horse have numerous interuption.

Regarding the connention between the presylvian and lateral rhinal sulci, the present result is similar to that observed by DELIMANN/MCCLURE (1975) in ruminants; EL-NAHLA (1982) in Egyptian buffalo and MANSOUR (1983) in camel. However EI-KHALIGI (1977) in camel and DELLMANN/MCCLURE (1975) in horse stated that the presylvian sulcus joins the lateral rhinal sulcus at the middle of the rostral piriform lobe.

In the donkey the proreus sulcus does not join the lateral rhinal sulcus a case which was observed by RAO/SHARMA (1974) in Indian buffalo, MANSOUR (1983) in camel, and AMIN (1984) in goat. The sulcus is inconstant in dog and when present it is united with the presylvian sulcus MEYER (1964). However DELLMANN/McCLURE (1975) in horse mentioned nothing about this sulcus. .

The present results show that the extention of the suprasylvian sulcus are simialr to that recorded by DELLMANN/MCCLURE (1975) in horse RAGHAVAN/KACHROO (1964) in ox, RAO/SHARMA (1974) in Indian buffalo and El-NAHLA (1982) in Egyptian buffalo. In the camel El-KHALIGI (1977) reported that the sulcus terminates into several sulci winding around the occipital pole. Also MANSOUR (1983) reported in the same animal, that the sulcus may terminate just rostral to the caudal pole of the cerebral hemisphere or curves ventromedially around the caudal pole to terminate by $2-3$ short branches in the tentorial aspect of the hemisphere. Concerning the division of the sulcus into rostral, middle and caudal suprasyivian sulci the present findings are in agreament with that of KANAN (1973), El-KHALIGI (1977) and MANSOUR (1983) in the camel and in dog as stated by MEYER (1964), However DELLMANN/McCLURE (1975) in horse, RAO/SHARMA (1974) in Indian buffalo found that the sulcus is divided into rostral and caudal parts only by the sulcus obliquus.

In the donkey the marginal sulcus runs along the caudal half of dorsal border of the hemisphere as in camel (El-KHALIGl, 1977), (RAGHAVAN KACHROO, 1964) cow and buffalo (RAO/SHAPMA, 1974 and EL-NAHLA, 1982), however this sulcus was observed in camel by MANSOUR (1983) to begin at the junction of the caudal two thirds of the hemispher.

The caudal termination of the marginal sulcus in the donkey is not similar to that mention ed by previous authors, where they reported that the sulcus terminates at the tentorial surface of the hemisphere.

The position of the endomarginal suicus at the caudal third of the dorsal border and parallel to it is similar to that reported by SISSON/GROSSMAN (1969) in horse and pig, KANAN (1973) and EI-KHALIGI (1977) in camel and by EI-NAHALA (1982) in Egyptian buffalo.

Concerning the beginning of the ansate sulcus, the present result is in agrrement with DELLMANN/MCCLURE (1975) in horse who stated that this sulcus originated from sulcus spleniaiis, MANSOUR (1983) in the camel reported that this sulcus is separated from the sulcus splenialis by a narrow gyrus, while EL-KHALIGI (1977) in the same animal stated that the ansate sulcus begins from the middle of the endogenual sulcus. In the donkey the ansate sulcus at its termination joins the suprasylvian sulcus as in horse (DELIMANN/McCLURE, 1975), pig (SLEFERIE, 1975) and goat (AMIN, 1984), while in camel (MANSOUR, 1983) this sulcus is separted from

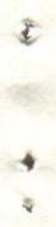

Assiut Vet. Med. J. Vol. 14, No. 28, 1985. 


\section{THE SULCI OF THE NEOPALUM OF THE DONKEY IN EGYPT}

the suprasylvian sulcus by a narrow gyrus. SISSON/GROSSMAN (1969) stated that in ox the transverse sulcus. SIEFERLE, (1975) added that this sulcus is a characteristic sulcus for ungulates.

The sulcus cruciatus in the present work is similar to that recorded in the horse by DELLLMANN/MCCLURE 61975), in the camel by MANSOUR (1983) and in the goat by AMIN (1984). While El-KHALIGI (1977) in the camel mentioned that the sulcus cruciatus unites with the sulcus genualis and sulcus rostralis internus.

The shape and position of the spenial sulcus in the donkey is similar to that recorded by DELIMANN/McCLURE (1975) in horse RAGHAVAN/KACHROO (1964) in ox, RAO/SHARMA (1974) in Indian buffalo and MEYER (1964) in dog. While MANSOUR (1983) in the camel and DELLMANN/MCCLURE (1975) in the pig reported that this sulcus lies about equidistance between the corpus callosum and the dorsal border of the cerebral hemisphere, and rostrally it is located close to this border.

The sulcus calcarinus is the direct caudal continuation of the donkey as well as in the horse 6SISSON/GROSSMAN, 1969), ox (RAGHAVAN/KACHROO, 1964) and camel (MANSOUR, 1983) and terminates just behind the depression for the rostral calliculi as in horse (SISSON/GROSSMAN, 1969 and SEIFERLE, 1975) and ox (RAGHAVAN/KACHROO, 1964, SEIFELE, 1975) without communication with the caudal part of the lateral sulcus.

The present results show that the course, position and relation of the cerebral sulci in donkey are generally similar to thsoe of other equines.

\section{REFERENCES}

Amin, M.E. (19844): Some anatomical studies on the brain of the goat. Thesis Ph.D. (Anatomy). Fac. of Vet. Med. Alexandria Univ.

Bradley. O.C. and T. Grahame (1947): The topographical anatomy of the head and neck of the horse, 2nd. ed. W. Green and son, Limited, Edinburgh.

Dellmann, H.D. and R.C. McClure (1975): Equine nervous system, central nervous system. In SISSON and GROSSMAN; the anatomy of the domestic anestic animals. Rev. by GETTY, 5th ed. W.B. Saundens Company, Philadelphia, London, Toronto.

(1975): Ruminant nervous system In: SISSON and GROSSMAN; the anatomy of the domestic animals. Rev. by EGTTY,5th ed. W.B.Saunders Company, Philadelphia, London, Toronto.

- (1975): Porcine nervous system In: SISSON and GROSSMAN; the anatomy of the domestic animals. Rev. by GETTY, Sth ed. W.B. Saunders Company, Philadelphia, London, Toronto.

El-KHALIGI, G.E.M. (1975): Some prenatal and postnatal morphological features of the brain of the one-humped camel. Thesis Ph.D. (Anatomy). Faculty of Vet. Med. Cairo
Univ,

EI-NAHLA, S.M.M. (1982): Some gross anatomical studies on the prenatal and postnatal morphological features of the brain of the water buffalo in Egypt. Ph.D. These (Anatomy).

Kanan, C.V. (1973): The external configuration of the cerebral hemispheres of the camel (Camelus dromedarius) Act Anat. 85, 145-152.

Mansour. A.A. (1983): The external canatomical fearures of system anervosum central of camelus dromedarius Ph.D. Theses (Anatomy) Fac. of Vet. Med. Assiut Univ.

Meyer, H. (1964): The brain in MILLER, M.E./G.C. CHRISTENSEN and H.E. EVANS (1964): The anatomy of the dog W.B. Saunders Co. Philadelphia, London.

Assiut Vet. Med. J. Vol. 14, No. 28, 1985. 


\section{8}

\section{A. HIFNY, et al.}

Nomina Anatomica Veterinaria (1973): Publ. by Int. committe on vet. Nomenclature of the world Ass. Vet. Anat. Znd ed., vienna.

Raghavan, D. and P. Kachroo (1964): Anatomy of the ox. Indian council of Agricultural Research. New Delhi, 1st ed.

RAO, S. and U.K. Sharma, (1974): Morphological study on the brain of Indian buffalo (Pubalis) with particular to the sulci. Indian J. animal sciences. 44 (3). 178-182.

Seiferile, E. (1975): Nervous system in NICKEL, R./A. SCHUMMER and E. SEIFERIE: Lehrbuch der anatomie der anatomie der haustiere Bd. IV. Verlag paul Parey. Berlin and Hamburg.

Sisson, S. and J.D. Grossman (1969): Anatomy of the domestic animals, 4th ed. W.B. Saunders Company, Philadelphia, London. 


\section{LEGENDS}

Fig. (1): Brain of the Donkey, lateral view :

1- fissura sylvia.

2- rostral branch of 1.

3- middle branch of 1 .

4- caudal branch of 1 .

5- sulcus presyivius.

6- sulcus proreus.

7- sulcus ectosylvis rostralis.

8- sulcus ectosylvius medius,

9- sulcus ectosylvius caudalis.

10- sulcus obliquus.

11- sulcus suprasylvius rostralis.

12- sulcus suprasylvius medius.

13- sulcus suprasylvius caudalis.

14- sulcus rhinalis lateralis, pars rostralis.

15- sulcus rhinalis lateralis, pars caudalis.

16- sulcus ectomarginalis.

Fig. (2): Brain of the Donkey, dorsal view :

1 - sulcus marginalis.

2- sulcus endomarginalis.

3- sulcus ectomarginalis.

4- sulcus ansatus.

5- sulcus presylvius.

6- sulcus cruciatus.

7- sulcus suprasylvius.

8- gyrus ectomarginalis.

9- gyrus ectosylvius.

10- gyrus postcruciatus.

11 - gyrus precruciatus.

Fig- (3): Brain of the donkey, medial view :

1- sulcus ansatus.

2- sulcus cruciatus.

3- suicus rostralis internus.

4- sulcus genualis.

5- sulcus splenialis.

6- sulcus calcarinus.

7- sulcus corporis callos.

8- gyrus cinguli.

9- gyrus marginalis.

10 - gyrus postcruciatus.

11 - gyrus precruciatus.

12 - gyrus proreus.

13- medial rhinal sulcus.

Assit Vet. Med. J. Vol 14, Na 28, 1985. 
9

I

Fig. (1)

Fig. (2)

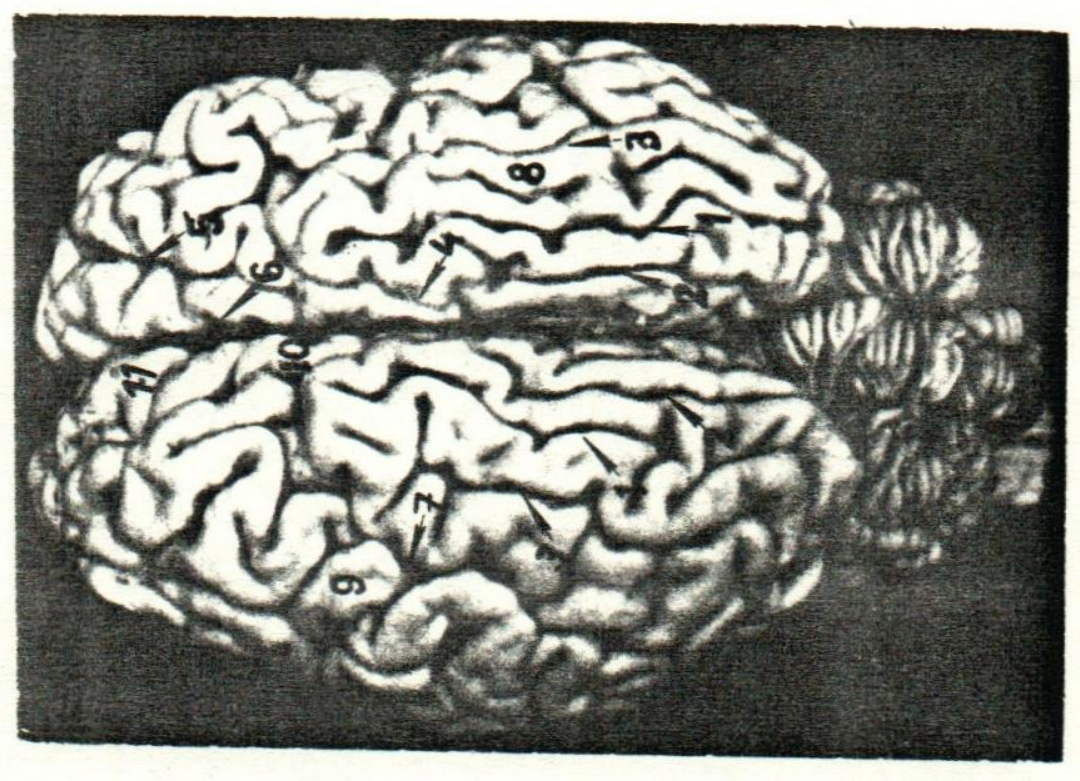

Fig. (3)

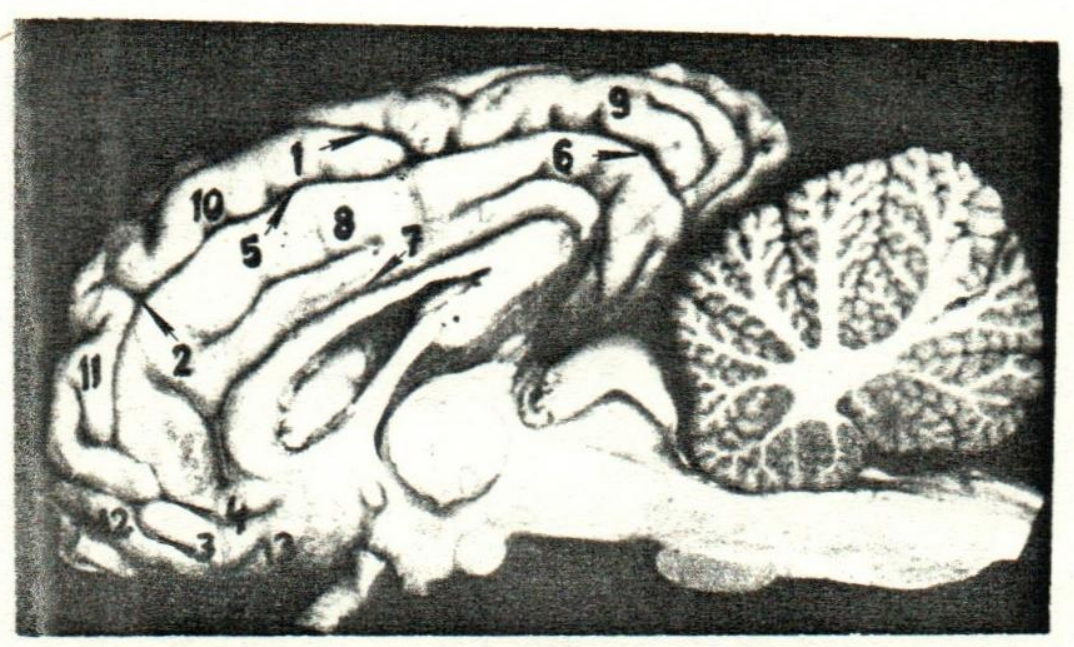


